UNIVERSITE DE LAUSANNE - FACULTE DE BIOLOGIE ET DE MEDECINE HOPITAL OPHTALMIQUE JULES GONIN

Ex-PRESS R-50 miniature glaucoma implant insertion under the conjunctiva combined with cataract extraction

\author{
THESE \\ préparée sous la direction du \\ Professeur associé André Mermoud \\ et présentée à la Faculté de biologie et de médecine de \\ l'Université de Lausanne pour l'obtention \\ du grade de \\ DOCTEUR EN MEDECINE \\ par \\ Delphine RIVIER \\ Médecin diplômée de la Confédération Suisse \\ Originaire de Lausanne (VD), Aubonne (VD) et Genève (GE) B MTE 3400 \\ Lausanne \\ 2008
}




\section{Rapport de synthèse}

Le glaucome à angle ouvert est une neuropathie optique chronique progressive pour laquelle de nombreux traitements tant médicaux que chirurgicaux ont été proposés. La prise en charge chirurgicale s'articule principalement autour de deux chirurgies filtrantes, la trabéculectomie et la sclérectomie profonde avec implant de collagène. Cependant, les complications postopératoires de ces deux interventions étant relativement fréquentes, la recherche s'est orientée vers des traitements alternatifs dont la mise en place de micro-drains. Ces implants de drainage diminuent la pression intraoculaire en créant un court-circuit du flux d'humeur aqueuse de la chambre antérieure vers l'espace sous-conjonctival avec formation d'une bulle de filtration. L'implant Ex-PRESS R-50 est un implant miniature $(2.5 \mathrm{~mm}$ de long pour $400 \mu \mathrm{m}$ de diamètre) en acier inoxydable et biocompatible.

La présente étude s'est proposée d'étudier l'efficacité et la sécurité de l'implant miniature Ex-Press R-50 lors d'une opération combinée cataracte-glaucome. Trentecinq yeux de 35 patients (âge moyen: 75 ans) ont été inclus dans l'étude. Tous les patients ont bénéficié d'une opération de la cataracte par phacoemulsification et mise en place d'un implant de chambre postérieure suivie de l'implantation du micro-drain. Les pressions intraoculaires préopératoires et postopératoires, la meilleure acuité visuelle corrigée, le nombre de médicaments anti-glaucomateux ainsi que le type et le nombre de complications ont été évalués mensuellement puis tous les 6 mois pendant 4 ans. Le succès total a été défini par une pression postopératoire finale inférieure à $18 \mathrm{mmHg}$ sans traitement médical associé, le succès partiel par une pression postopératoire finale inférieure à $18 \mathrm{mmHg}$ avec ou sans traitement médical associé.

Le suivi moyen a été de 36.9 mois avec une baisse de la pression intraoculaire significative d'environ $25 \%$. Une augmentation de l'acuité visuelle a été observée après l'opération de la cataracte et le nombre de médicaments anti-glaucomateux a été réduit de $57 \%$. Dix patients ont bénéficié d'un traitement supplémentaire de la bulle de filtration par injection d'anti-métabolite (mitomycine $\mathrm{C}$ ). Nous avons observé 8 complications majeures (4 érosions conjonctivales et 4 obstructions de l'orifice interne du micro-drain), toutes suivies de l'ablation de l'implant et de la réalisation d'une chirurgie classique du glaucome. En se basant sur les courbes de KaplanMeier à 48 mois, le taux de succès total était de $32.7 \%$ et le succès partiel de $53.7 \%$.

Nous pouvons conclure suite à ce travail que l'implant miniature Ex-PRESS R-50 est associé à un nombre trop élevé de complications, même si les cas non compliqués ont bénéficié d'une baisse significative de la pression intraoculaire. La modification de l'architecture du micro-drain ainsi que de la technique chirurgicale devrait augmenter le taux de succès. 


\title{
EX-PRESS R-50 miniature glaucoma implant insertion under the conjunctiva combined with cataract extraction
}

\author{
Delphine Rivier, MD, Sylvain Roy, MD, MSc, André Mermoud, MD
}

\begin{abstract}
PURPOSE: To evaluate the efficacy and safety of the Ex-PRESS R-50 implant (Optonol Ltd.) in eyes
\end{abstract} operated on for open-angle glaucoma combined with phacoemulsification. SETTING: Glaucoma Unit, Ophthalmology Department, University of Lausanne, Lausanne,
Switzerland.

METHODS: Between November 2000 and June 2002, the Ex-PRESS R-50 shunt was implanted in 35 eyes of 35 patients. The best corrected visual acuity (BCVA), intraocular pressure (IOP), number of medications, and complications were recorded preoperatively as well as postoperatively at 1 and 7 days and $1,2,3,6,9,12,24,36$, and 48 months. Temporal clear corneal phacoemulsification with intraocular lens implantation was performed first. The ophthalmic viscosurgical device was not removed, and the Ex-PRESS R-50 was implanted under the conjunctiva into the anterior chamber.

RESULTS: The mean follow-up was 36.9 months \pm 18.2 (SD) and the mean age of the patients, $74.6 \pm 10.9$ years. The mean preoperative IOP of $19.3 \pm 6.3 \mathrm{~mm} \mathrm{Hg}$ decreased postoperatively to $15.3 \pm 6.2 \mathrm{~mm} \mathrm{Hg}, 15.1 \pm 4.6 \mathrm{~mm} \mathrm{Hg}, 13.8 \pm 2.8 \mathrm{~mm} \mathrm{Hg}, 14.6 \pm 2.9 \mathrm{~mm} \mathrm{Hg}$, and $13.3 \pm$ $2.0 \mathrm{~mm} \mathrm{Hg}$ at 6 months, 12 months, 24 months, 36 months, and 48 months, respectively $(P<.005)$. At 48 months, the mean BCVA was $0.74 \pm 0.34$ and the number of medications was reduced by $57 \%(P<, 005)$. The microtube was removed in 10 patients, and bleb management was performed in 10 eyes. Ten patients (32\%) had satisfactory IOP control (mean $13.2 \pm 2.2 \mathrm{~mm} \mathrm{Hg}$ ) without medication; minor transient complications were observed in 10 patients. Based on the cumulative survival curve after 48 months, the complete success rate was $32.7 \%$ and the qualified success rate, $53.7 \%(P<.05)$.

CONCLUSIONS: EX-PRESS R-50 implantation under the conjunctiva was associated with a relatively high number of complications, despite good IOP control in the uncomplicated cases. Refinement in the tube design and implantation technique would increase the success rate.

$J$ Cataract Refract Surg 2007; 33:1946-1952 (c) 2007 ASCRS and ESCRS

Deep sclerectomy with collagen implant surgery was initially designed to lower the complication rates encountered with the most commonly used penetrating procedure, trabeculectomy, ${ }^{1}$ Complications included hyphema, anterior chamber inflammation, excessive filtration leading to hypotony, a flat anterior chamber, surgery-induced cataract, choroidal detachment, hypotony-related maculopathy, and endophthalmitis. Because deep sclerectomy is a nonpenetrating procedure, most complications were avoided or significantly reduced. Despite these advantages, the technique has drawbacks, such as a relatively long learning curve and a delicate surgical technique, that explain the relatively high rate of conversion from deep sclerectomy to trabeculectomy during surgery. ${ }^{2}$
To alleviate the complications, the search for alternative treatments to conventional glaucoma filtering surgery has intensified and penetrating filtering surgery using miniature glaucoma drainage devices has gained renewed interest since the introduction of large drainage devices almost a century ago. 3,4 These devices create alternative aqueous pathways by draining aqueous from the anterior chamber through a long tube to an equatorial plate that promotes bleb formation. ${ }^{5}$ They have been commonly used in refractory glaucoma when other modes of treatment, nonsurgical and surgical, have failed. ${ }^{6,7}$ Results in such cases of complicated glaucoma were difficult to analyze, and no definitive conclusions could be drawn from these studies. However, experience in the use of such 
devices led to several modifications in their design and construction and in the techniques for their implantation. ${ }^{8}$

The first miniature glaucoma implant, the Ex-PRESS R-50 (Optonol Ltd.), was developed in 1998. The implant is a nonvalved device that is implanted at the limbus to drain aqueous humor from the anterior chamber to the subconjunctival space, creating a conjunctival filtration bleb, similar to trabeculectomy. ${ }^{9}$

Several articles on the Ex-PRESS R-50 implant have been published. Five studies of 26, 24, 16, 50, and 99 eyes, respectively, found encouraging results with a safe and efficient procedure. ${ }^{10-14}$ Two case series with 11 and 4 eyes, respectively, and 1 case report concluded that the complication rate was unacceptably high, in particular with respect to the risk for endophthalmitis after conjunctival erosion. ${ }^{15-17}$

The purpose of this study was to evaluate the efficacy and safety of the Ex-PRESS R-50 miniature glaucoma implant placed under the conjunctiva in reducing intraocular pressure (IOP) in eyes operated on for open-angle glaucoma combined with phacoemulsification and posterior chamber intraocular lens (PC IOL) implantation.

\section{PATIENTS AND METHODS}

In this nonrandomized nonmasked prospective trial, the EX-PRESS R-50 microtube was implanted in 35 eyes of 35 patients at the Glaucoma Unit, Ophthalmology Department, University of Lausanne, between November 2000 and June 2002. The patients, nonconsecutive cases, were enrolled in this study after formal approval by the Ethical Committee of the University of Lausanne. Preference for this technique over other filtering surgery was based on the patient's willingness to participate in the study. Each patient received a comprehensive explanation of the study

Accepted for publication June 19, 2007.

From the Glaucoma Unit, Jules Gonin Eye Hospital, University of Lausanne, Lausanne, Switzerland.

No author has a financial or proprietary interest in any material or method mentioned.

Presented at the III International Congress on Glaucoma Surgery, Toronto, Ontario, Canada, May 2006 (with financial support of Swiss National Science Foundation grant 3200B0-103603/1).

Supported by the Swiss National Science Foundation grant 32-64103.00.

Tyler Tacher, Lausanne Swiss Federal Institute of Technology, read and corrected the text of the submitted manuscript.

Corresponding author: Dr. Sylvain Roy, Glaucoma Unit, Jules Gonin Eye Hospital, Avenue De France 15, CH-1004 Lausanne, Switzerland. E-mail: sylvain.roy@epfl.ch. and its implications and signed a written informed consent before surgery.

Patients eligible for the study were older than 18 years. All had medically uncontrolled primary open-angle glaucoma (POAG) or pseudoexfoliative glaucoma (PXFG) associated with cataract. Uncontrolled glaucoma was defined as elevated IOP, a progression of optic nerve cupping, and/or deterioration of the visual field as assessed by an experienced glaucoma specialist. Patients who had side effects from antiglaucoma medication and eyes that required good IOP control without medication were also included. All eyes were under maximum tolerated medical therapy ( 2 or more antiglaucoma medications), had previous filtering surgery that failed, or both. In eyes with a previous failed filtering surgery, the quadrant used to implant the Ex-PRESS R-50 microtube was different from that in the initial surgery. This approach was used to minimize interference with possible conjunctival scarring or remodeling reaction from the former surgery. The mean decrease in preoperative best corrected visual acuity (BCVA) was mainly due to cataract development. The lens opacities estimation was made by slitlamp examination, and this assessment was used for the indication of a combined procedure when glaucoma surgery was concomitantly required. Cataract extraction was proposed when the mean preoperative BCVA was worse than 0.7 or the patient reported disturbing glare in the presence of lens opacities.

Eyes with angle-closure glaucoma, normal-tension glaucoma, neovascular glaucoma, or congenital or juvenile glaucoma were excluded from the study. Filtering surgery performed less than 1 year before enrollment in this study and a monocular status were also criteria for exclusion.

The primary outcome measure was the IOP. The secondary outcome measures were BCVA, use of antiglaucoma medications, and type and number of perioperative or postoperative complications. Based on the cup-to-disc ratio, the severity of glaucoma was classified into 3 groups: early $(0.30$ to 0.59$)$, moderate $(0.60$ to 0.79$)$, and severe $(0.80$ to $1.00)$.

\section{Data Recorded Preoperatively}

On enrollment, all patients had a comprehensive ophthalmic examination that included measurement of the distance BCVA using Snellen charts at $6 \mathrm{~m}$, anterior segment slitlamp biomicroscopy, fundus evaluation, a single-reading IOP measurement with a Goldmann applanation tonometer (without diurnal fluctuation taken into account), and automated visual field evaluation (Octopus 101, Haag-Streit) within 6 months before enrollment.

\section{Glaucoma Drainage Implant}

The Ex-PRESS R-50 implant is a miniature glaucoma drainage device made of biocompatible stainless steel. ${ }^{9}$ The tube is $2.50 \mathrm{~mm}$ in overall length, with $2.00 \mathrm{~mm}$ being intraocular. The external diameter is approximately $400 \mu \mathrm{m}$ (27 gauge) and the inner bore, $50 \mu \mathrm{m}$. A detailed description of the Ex-PRESS R-50 technique has been published."

\section{Surgical Technique}

All operations were performed by the same experienced ophthalmic surgeon (A.M.) using retrobulbar anesthesia consisting of 2 to $4 \mathrm{~mL}$ of a bupivacaine $0.75 \%$, lidocaine hydrochloride $4 \%$, and 50 IU hyaluronidase mixed solution. 
A retrobulbar procedure was preferred to peribulbar to prevent an increase in IOP during injection of the solution. Temporal sutureless clear corneal phacoemulsification cataract extraction with in-the-bag acrylic hydrophilic foldable intraocular lens (IOL) implantation was performed first through a $3.5 \mathrm{~mm}$ incision; the ophthalmic viscosurgical device (OVD) was left in the anterior chamber. For implantation of the Ex-PRESS R-50 device, a 2.0 to $4,0 \mathrm{~mm}$ circumferential conjunctival opening was created 10.0 to $15.0 \mathrm{~mm}$ posterior to the limbus. The device, mounted on its introducer, was slid under the conjunctiva and Tenon's capsule into the anterior chamber and implanted radial to the limbus and parallel to the iris through a preincision made with a 27gauge needle $2.0 \mathrm{~mm}$ from the limbus. The introducer was then withdrawn and the conjunctiva closed with an 8-0 polyglactin (Vicryl) running suture. No patch, such as Tutoplast or a graft, was used to cover the implant. The time required to implant the device was approximately 3 minutes. Postoperative treatment consisted of topical application of tobramycin and dexamethasone 5 times a day followed by gradual tapering over approximately 4 weeks.

\section{Success Criteria}

Surgery was considered a complete success when the IOP was $18 \mathrm{~mm} \mathrm{Hg}$ or less and $6 \mathrm{~mm} \mathrm{Hg}$ or more without medication. The same criteria with or without medication were used to define qualified success. Surgery was considered a failure when IOP was higher than $18 \mathrm{~mm} \mathrm{Hg}$ despite medication and/or further glaucoma surgery was required or the implant explanted. Patients having removal of the implant, and thus considered failed cases, were not included in the subsequent postoperative follow-ups. Postoperative bleb management and fibrosis modulation using the needling technique, with or without mitomycin-C (MMC) injection, were not a criterion for failure; in such cases, the patient data were classified as qualified success.

\section{Postoperative Follow-up}

The BCVA, IOP, number of medications, and complications were recorded preoperatively as well as 1 and 7 days and $1,2,3,6,9,12,24,36$, and 48 months after surgery. Follow-up was more frequent when required by the clinical situation.

Any complication was recorded and was defined as major or minor based on the clinical significance and importance over time. Evaluation of the complications was based on the surgeon's clinical experience. Cases of cornea-device contact and iris-device contact were assessed under slitlamp examination. Hyphema was considered present when blood collection was seen in the anterior chamber. Anterior chamber depth was clinically assessed under slitlamp examination and was considered shallow when iridocorneal touch in the periphery was noticed. Choroidal detachment was observed under indirect ophthalmoscopy, Complications were considered minor if they resolved spontaneously or required minimal surgical revision. The major complications required removal of the device and further filtering surgery.

When the filtering bleb at any postoperative visit was encysted or showed signs of fibrosis leading to an increase in IOP, subconjunctival injections of MMC were administered. The subconjunctival injections consisted of 0.05 to $0.1 \mathrm{~mL}$ of a MMC $0.02 \%$ solution injected beneath the filtering bleb under topical anesthesia. Neodymium:YAG (Nd:YAG) capsulotomy (Microruptor V, Meridian AG) was performed when visual acuity was reduced as a result of posterior capsule opacification. Neodymium:YAG laser synechialysis was done to liberate synechia when the tube was obstructed by iris strands.

\section{Statistical Analysis}

Data are expressed as the mean $\pm \mathrm{SD}$ (minimum and maximum). Results were analyzed using a 1-way analysis of variance (ANOVA) and Student $t$ test for parametric data (IOP), Wilcoxon signed-rank test for nonparametric data (BCVA, number of medications), and Kaplan-Meier survival curves at the end of follow-up using the log-rank test. Results were considered significant when $P<.05$.

\section{RESULTS}

The Ex-PRESS R-50 device was easily implanted without perioperative complications in 35 eyes of 35 white patients with glaucoma and cataract. The mean age of the patients was 74.6 years \pm 10.9 (SD) (range 49 to 90 years). Table 1 shows the patients' data.

The mean follow-up was $36.9 \pm 18.2$ months (range 3.7 to 37.1 months). Twenty-eight, 26, 24, and 21 patients completed the 1-, 2-, 3-, and 4-year follow-up, respectively. Three patients died, and 1 was lost to follow-up.

Mean preoperative IOP (Table 1) decreased after surgery by $21 \%$ (mean $15.3 \pm 6.2 \mathrm{~mm} \mathrm{Hg}$; range 7 to

Table 1. Patient data $(N=35)$.

\begin{tabular}{|c|c|}
\hline Parameter & Result \\
\hline Eyes, $\mathrm{n}$ & 35 \\
\hline Male/female, n (\%) & $12(34.3) / 23(65.7)$ \\
\hline Mean age $(y) \pm S D$ & $74.6 \pm 10.9$ \\
\hline White ethnicity, $\mathrm{n}(\%)$ & $35(100)$ \\
\hline \multicolumn{2}{|l|}{ Diagnosis } \\
\hline POAG & $22(62.9)$ \\
\hline PXFG & $13(37.1)$ \\
\hline Mean follow-up $(\mathrm{mo}) \pm \mathrm{SD}$ & $36.9 \pm 18.2$ \\
\hline Lost to follow-up, n (\%) & $4(11.4)$ \\
\hline \multicolumn{2}{|l|}{ Preoperative data } \\
\hline \multicolumn{2}{|l|}{$\mathrm{IOP}(\mathrm{mm} \mathrm{Hg})$} \\
\hline Mean \pm SD & $19.3 \pm 6.3$ \\
\hline Range & 10-35 \\
\hline \multicolumn{2}{|l|}{ Snellen BCVA } \\
\hline Mean $\pm S D$ & $0.47 \pm 0.3$ \\
\hline Range & $0.01-1.00$ \\
\hline Mean medications ( $n$ ) per patient $\pm S D$ & $2.1 \pm 1.1$ \\
\hline Previous glaucoma surgery, n (\%) & $3(8.5)$ \\
\hline \multicolumn{2}{|l|}{ Severity of glaucoma (c/d ratio) } \\
\hline Early $(0.3-0.59)$ & $10(28.6)$ \\
\hline Moderate $(0.6-0.79)$ & $9(257)$ \\
\hline Severe $(\geq 0.8)$ & $16(45.7)$ \\
\hline
\end{tabular}


$38 \mathrm{~mm} \mathrm{Hg})$ at 6 months, $22 \%(15.1 \pm 4.6 \mathrm{~mm} \mathrm{Hg}$; 10 to $30 \mathrm{~mm} \mathrm{Hg}$ ) at 12 months, $29 \%(13.8 \pm 2.8 \mathrm{~mm} \mathrm{Hg}$; 9 to $18 \mathrm{~mm} \mathrm{Hg})$ at 24 months, $24 \%(14.6 \pm 2.9 \mathrm{~mm} \mathrm{Hg}$; 10 to $19 \mathrm{~mm} \mathrm{Hg})$ at 36 months, and $31 \%(13.3 \pm 2.0$ $\mathrm{mm} \mathrm{Hg} ; 10$ to $17 \mathrm{~mm} \mathrm{Hg}$ ) at 48 months. The drop was significant between the preoperative and all postoperative periods $(P<.005$, ANOVA and Student $t$ test). The IOP curve dropped 1 week after surgery; the drop was followed by a slight rise that stabilized at approximately $14 \mathrm{~mm} \mathrm{Hg}$ without a significant variation in the IOP between 1 month and 48 months (Figure 1).

The mean preoperative BCVA (Table 1 ) increased to $0.74 \pm 0.34$ (range 0.05 to 1.00$)$ at 48 months $(P=$ $.0003)$. The BCVA increase was slightly limited $(<1.0)$ due to systemic or retinal disease not related to the initial glaucoma diagnosis. The postoperative complications had no effect on the visual outcomes. Four patients had a BCVA worse than 0.6 as a result of vascular trouble $(n=2)$ or age-related macular degeneration $(n=2)$.

The reduction in antiglaucoma medication after implantation of the Ex-PRESS R-50 device was 57\% at 48 months, at which time 11 patients (35\%) were receiving pharmacological treatment $(P<, 05) ; 4$ patients were on 1 medication, 6 were on 2, and 1 was on 3. The number of antiglaucoma medications slightly increased over time (mean 0.4 at 6 months and 0.9 at 48 months) (Figure 2). This was probably due to a progressive loss of efficacy in the device's filtering function, despite good IOP control.

Postoperative bleb management and fibrosis modulation were performed in 10 eyes $(28.6 \%)$. The treatment included needling with or without MMC injections and Nd:YAG capsulotomy (Table 2).

Table 3 shows the postoperative complications. The minor complications resolved spontaneously in less

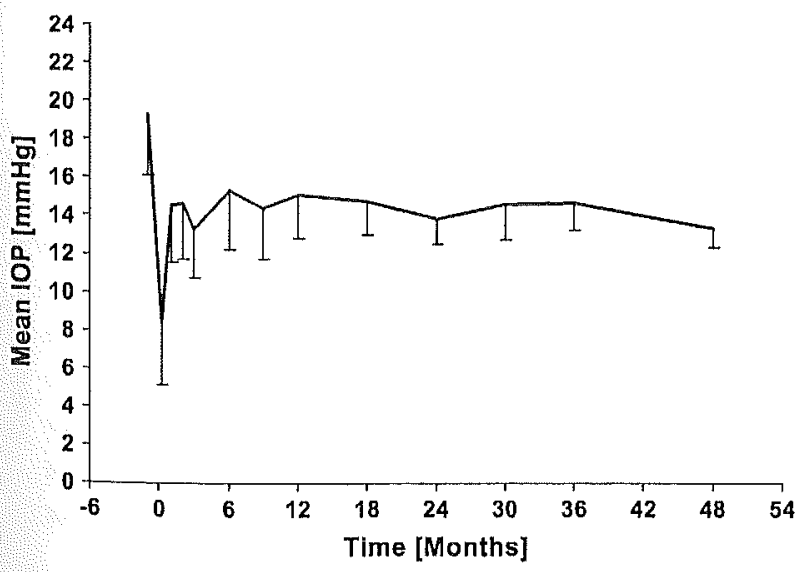

Figure 1. Mean IOP before surgery and at each follow-up period. The bars represent the SD,

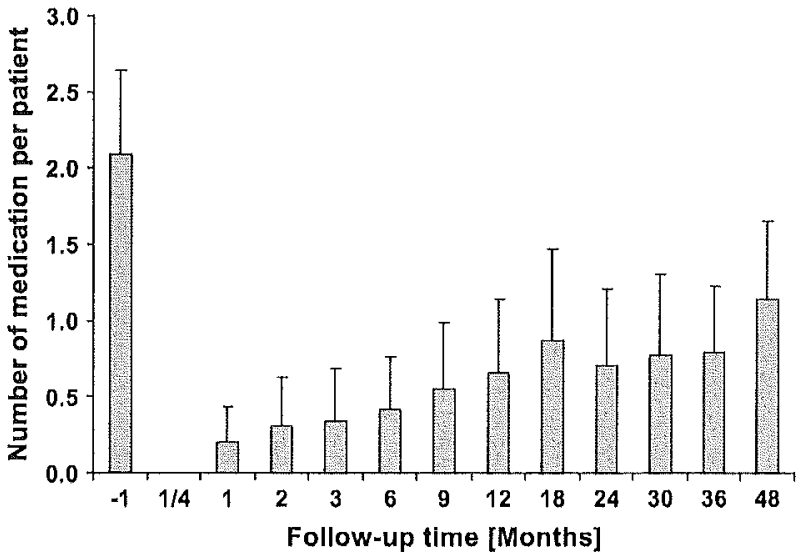

Figure 2. Mean number of medications before surgery and at each follow-up period. The bars represent the SD.

than a month in 7 of the 10 cases. In the eye that developed a shallow anterior chamber, the chamber required inflation with an injection of an OVD. An $\mathrm{Nd}$ :YAG laser iridoplasty was performed in an attempt to solve the problem created by the iris-device contact. The contact did not resolve; thus, the eye required further surgical treatment. The cystic Tenon's capsule did not resolve despite revision of the filtering bleb consisting of a tenonectomy and synechialysis.

Major complications occurred in 8 cases (Table 3). The cases of conjunctival erosion were induced by a protruding dislodged device. In the cases of complete tube obstruction, there was significant and rapid elevation in IOP over early postoperative (1 to 8 week) values. Two obstructions occurred in patients with PXFG and 2 in patients with POAG.

The device was removed in all eyes with complications, all of which required further glaucoma filtering surgery. In 1 eye with conjunctival erosion, an attempt was made to implant a new Ex-PRESS R-50 device. This was followed by a new conjunctival erosion that required surgical removal of the new device. Three eyes that required tube removal had previous bleb management with $\mathrm{MMC}$ injection; the reasons for

\begin{tabular}{|lc|}
\hline \multicolumn{2}{|l|}{ Table 2. Postoperative interventions, } \\
\hline & \multicolumn{1}{c|}{ Eyes } \\
\cline { 2 - 2 } Intervention & Number $(\%)$ \\
\hline Needling with MMC & $6(17.1)$ \\
Needling without MMC & $4(11.4)$ \\
Nd:YAG capsulotomy & $5(14.3)$ \\
\hline MMC = mitomycin-C; Nd:YAG = neodymium:YAG & \\
\hline
\end{tabular}


Table 3. Postoperative complications.

\begin{tabular}{lc}
\hline Complication & Number (\%) \\
\hline Minor & $1(2.9)$ \\
$\quad$ Cornea-device contact at 1 day & $1(2.9)$ \\
Hyphema <2.0 mm at 1 day & $1(2.9)$ \\
Shallow anterior chamber requiring & $5(14.3)$ \\
reformation & $1(2.9)$ \\
$\quad$ Choroidal detachment in first postop week & $1(2.9)$ \\
Iris-device contact at 8 months & $4(11.4)$ \\
Fibrosis of Tenon's capsule at 10 months & $4(11.4)$ \\
Major & $10(28.6)$ \\
Erosion of the conjunctiva at $2,6,9$, or 12 & \\
months & Obstruction of the tube at 6 months $(\mathrm{n}=1)$ \\
and 18 months $(\mathrm{n}=3)$ & \\
Tube removal &
\end{tabular}

removing these tubes were tube occlusion in 2 eyes and conjunctival erosion in 1 .

At 48 months, based on the Kaplan-Meier survival curve, the cumulative qualified success rate was $53.7 \%$ and the complete success rate was $32.7 \%$ $(P<.05)$ (Figure 3). Based on IOP and surgical criteria, $48.0 \%$ of patients had failed surgery.

\section{DISCUSSION}

Our study of 35 eyes found a $31 \%$ reduction in IOP 48 months postoperatively with a cumulative qualified success rate of $53.7 \%$. Based on the percentage of IOP reduction, our results compare favorably with those in other studies. ${ }^{10-15}$ Our results were obtained with a mean number of antiglaucoma medications that increased slightly over time. However, considering the qualified success rate, our results were not as favorable

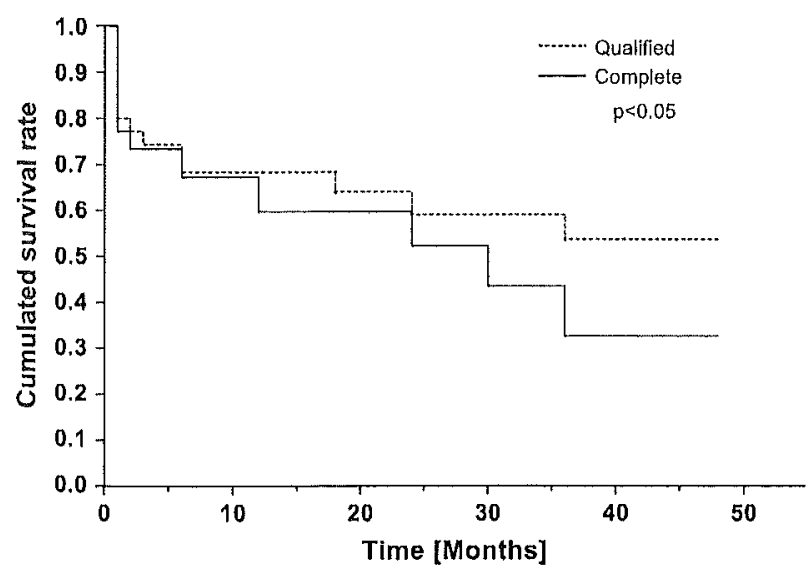

Figure 3, Qualified and complete cumulative success rate $(P<.05)$. as those reported in the literature for other filtering procedures; that is, $60 \%$ to $100 \%$ for trabeculectomy, ${ }^{18-19}$ up to $91 \%{ }^{20,21}$ for nonpenetrating surgery, and $45 \%$ to $80 \%$ for other glaucoma drainage devices. $^{22-25}$

Two studies of the Ex-PRESS R-50 implant using the same surgical approach have been published. Traverso et al. ${ }^{10}$ implanted the device in 25 eyes and obtained a qualified success rate of $76,9 \%$. Zarnowski et al, ${ }^{12}$ treated 16 eyes with a qualified success rate of $68 \%$. The authors report few complications, and both groups concluded that Ex-PRESS R-50 implantation is an effective and safe procedure. Their mean follow-up (23.9 months and 6.0 months, respectively) was shorter than ours ( $36.9 \pm 18.2$ months), and this could explain the different results.

Our results do not differ significantly from those of Wamsley et al. ${ }^{15}$ in terms of the degree of IOP reduction and the high rate of complications. Most complications we encountered were also observed by Stewart et al. ${ }^{16}$ in a small case series reporting complications after Ex-PRESS implantation and by Tavolato et al. ${ }^{17}$ in a case report of a spontaneous extrusion of the Ex-PRESS device. The preoperative glaucoma history of these eyes, including the previous surgeries, as well as the type and severity of glaucoma were probably important risk factors for failure. For example, of the 10 cases that eventually ended as a failure, 2 had previous glaucoma surgery for medically uncontrolled glaucoma.

In our study, the postoperative BCVA increased by approximately $60 \% 18$ to 24 months after surgery. This improvement was the direct benefit of cataract extraction. No patient had a postoperative BCVA lower that the preoperative BCVA.

The reduction in the mean number of medications was $57 \%$ at last follow-up. This result is encouraging; however, as the preoperative IOP was not significantly elevated, we essentially focused on lowering the number of medications rather than on IOP. The mean time before reintroducing medication was $10.5 \pm 0.3$ months (range 1 to 36 months) after surgery. Lachkar et $\mathrm{al}^{2 \cdot 1}$ report a mean time before restarting medications of 20.2 months after initial nonpenetrating deep sclerectomy and Chen et al., ${ }^{18}$ of 41 months after initial trabeculectomy. Both techniques decreased the mean number of antiglaucoma medications (by 58\% and $48 \%$, respectively) at the last postoperative followup. In our cases, the reintroduction of antiglaucoma medication occurred sooner; on the other hand, the quantity of drugs increased over time. This could reflect a progressive loss of efficacy in the device's filtering function. Four of the 8 major complications in our study were due to tube obstruction that required additional treatment. 
Studies of trabeculectomy report an increased rate of cataract development after surgery, ${ }^{26}$ a complication not reported at the same rate for the long-term results of deep sclerectomy. ${ }^{20}$ Therefore, it is interesting to contemplate a combined procedure that treats glaucoma and cataract at the same time without compromising either operation. For instance, some studies found better IOP reduction and a higher success rate when trabeculectomy was performed alone. ${ }^{27}$ Contrary to trabeculectomy, the effects of a nonpenetrating procedure did not appear to be compromised in terms of lowering IOP when combined with phacoemulsification and IOL implantation. ${ }^{28}$ When glaucoma drainage implants such as the Baerveldt tube or Molteno valve were used in conjunction with phacoemulsification, the results also seemed favorable. ${ }^{29}$ Comparing our results with those in studies that addressed the glaucoma issue only, no significant differences in IOP-lowering effect or success rate was found, ${ }^{12,15}$ While this conclusion could be compared with that reached for nonpenetrating surgery, follow-up and patient number were limited and further studies involving more patients and a longer follow-up period are required.

The surgical approach with the Ex-PRESS R-50 implant differs significantly from previously reported filtering techniques. The 2 major complications, tube obstruction and conjunctival erosion, may be due to the small inner bore, which can become increasingly clotted over time, and the plate touching the conjunctiva with significant rubbing of the edges of the plate.

To alleviate complications that are mainly the result of conflict between tube design and eye anatomy, we propose improvements. For instance, the length and tube geometry could be redesigned to prevent the lumen from clotting. Similarly, to prevent conjunctival erosion, the distal end of the tube should be protected by covering it under a superficial scleral flap. This technique has been successfully tested. ${ }^{9,13,14}$

Our study had limitations. The number of patients enrolled (35) was relatively small, although this figure compares favorably with that in other published papers on this topic. ${ }^{10-12,15}$ The design was nonmasked because the inner portion of the tube was visible to the investigators during slitlamp biomicroscopy examination. This could have led to an inevitable bias in the interpretation of the complications. Nevertheless, the investigators tried not to influence the qualification of the complications based on their possible individual conceptions about this procedure. The nonrandomized and nonconsecutive selection of patients could also have contributed, to a lesser extent, to some observer bias in proposing this technique based on individual presumptions. Again, care was taken to minimize such influence by performing the surgery based solely on the patient's clinical status and interest in being involved in the study. The strength of the study lies in the long follow-up and that the same technique was used by the same surgeon for all surgeries.

\section{CONCLUSION}

In this paper, we present the long-term results of a study of combined glaucoma and cataract surgery comprising phacoemulsification and PC IOL implantation followed by the implantation of the Ex-PRESS R-50 microtube. Of the 35 eyes analyzed, $10(32 \%)$ had satisfactory IOP control without medication. A third of the tubes had to be explanted due to major complications that required further glaucoma surgery. Reasons for this surgical failure were tube obstruction and conjunctival erosion. Modifications of the tube's geometry and the surgical technique may improve the efficiency and safety of the procedure.

\section{REFERENCES}

1. Mermoud A, Schnyder CC, Sickenberg $M$, et al. Comparison of deep sclerectomy with collagen implant and trabeculectomy in open-angle glaucoma. J Cataract Refract Surg 1999; 25; 323-331

2. Ambresin A, Shaarawy T, Mermoud A. Deep sclerectomy with collagen implant in one eye compared with trabeculectomy in the other eye of the same patient. J Glaucoma 2002; 11:214-220

3. Hong $\mathrm{C}-\mathrm{H}$, Arosemena A, Zurakowski D, Ayyala RS. Glaucoma drainage devices: a systematic literature review and current controversies. Surv Ophthalmol 2005; 50:48-60

4. Assaad $\mathrm{MH}$, Baerveldt $\mathrm{G}$, Rockwood EJ. Glaucoma drainage devices; pros and cons. Curr Opin Ophthalmol 1999; 10: 147-153

5. Molteno ACB. New implant for drainage in glaucoma; clinica trial. Br J Ophthalmol 1969; 53:606-615

6. Tsai JC, Johnson CC, Kammer JA, Dietrich MS. The Ahmed shunt versus the Baerveldt shunt for refractory glaucoma II; longer-term outcomes from a single surgeon. Ophthalmology 2006; 113:913 917

7. Hamard $\mathrm{P}$, Loison-Dayma $\mathrm{K}$, Kopel $\mathrm{J}$, et al. Glaucomes réfractaires et implant de Molteno: étude rétrospective des suites opératoires et des résultats d'une variante chirurgicale. [Molteno implant and refractory glaucoma: evaluation of postoperative IOP control and complications with a modified surgical procedure.]. J Fr Ophtalmol 2003; 26:15-23

8. Lim KS, Allan BDS, Lloyd AW, et al. Glaucoma drainage devices; past, present, and future. $\mathrm{Br} J$ Ophthalmol 1998; 82:1083-1089

9. Nyska A, Glovinsky $Y$, Belkin $M$, Epstein $Y$. Biocompatibility of the Ex-PRESS miniature glaucoma drainage implant. J Glaucoma 2003; $12: 275-280$

10. Traverso CE, De Feo F, Messas-Kaplan A, et al. Long term effect on IOP of a stainless steel glaucoma drainage implant (Ex-PRESS) in combined surgery with phacoemulsification. $\mathrm{Br}$ J Ophthalmol 2005; 89;425-429

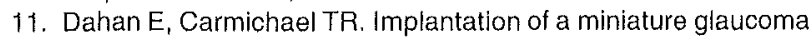
device under a scleral flap. J Glaucoma 2005; 14:98-102 
12. Zarnowski T, Kawa P, Rakowska E, Zagorski Z. Comparison of deep sclerectomy and miniature Ex-Press drainage device in open angle glaucoma. Ophthalmic Res 2001; 33(suppl 1):183

13. Maris PJG Jr, Ishida $K$, Netland PA. Comparison of trabeculectomy with Ex-PRESS miniature glaucoma device implanted under scleral flap. J Glaucoma 2007; 16:14-19

14. Coupin A, Li Q, Riss I. Implant miniature Ex-PRESS'M placé sous un volet scléral dans la chirurgie du glaucome à angle ouvert: étude rétrospective. [Ex-PRESS ${ }^{\mathrm{TM}}$ miniature glaucoma implant inserted under a scleral flap in open-angle glaucoma surgery: a retrospective study]. J Fr Ophtalmol 2007; 30:18-23

15. Wamsley S, Moster MR, Rai S, et al. Results of the use of the ExPRESS miniature glaucoma implant in technically challenging, advanced glaucoma cases: a clinical pilot study. Am J Ophthal$\mathrm{mol} 2004 ; 138: 1049-1051$

16. Stewart RM, Diamond JG, Ashmore ED, Ayyala RS. Complications following Ex-Press glaucoma shunt implantation. Am J Ophthalmol 2005; 140:340-341

17. Tavolato $M$, Babighian $S$, Galan A. Spontaneous extrusion of a stainless steel glaucoma drainage implant (Ex-PRESS). Eur J Ophthalmol 2006; 16:753-755

18. Chen TC, Wilensky JT, Viana MAG. Long-term follow-up of initially successful trabeculectomy. Ophthalmology 1997; 104:1120-1125

19. Robinson DIM, Lertsumitkul S, Billson FA, Robinson LP. Longterm intraocular pressure control by trabeculectomy: a tenyear life table. Aust N Z J Ophthalmol 1993; 21:79-85

20. Shaarawy $T$, Mansouri $K$, Schnyder $\mathrm{C}$, et al. Long term results of deep sclerectomy with collagen implant. J Cataract Refract Surg 2004; 30:1225-1231
21. Lachkar $Y$, Neverauskiene J, Jeanteur-Lunel M-N, et al. Nonpenetrating deep sclerectomy: a 6-year retrospective study. Eur J Ophthalmol 2004; 14:26-36

22. Wilson MR, Mendis $U$, Paliwal $A_{1}$ Haynatzka $V$. Long-term follow-up of primary glaucoma surgery with Ahmed glaucoma valve implant versus trabeculectomy. Am J Ophthalmol 2003 136:464-470

23. Roy S, Ravinet E, Mermoud A. Baerveldt implant in refractory glaucoma: long-term results and factors influencing outcome. int Ophthalmol 2001; 24:93-100

24. Taglia DP, Perkins TW, Gangnon R, et al. Comparison of the Ahmed Glaucoma Valve, the Krupin Eye Valve with Disk, and the double-plate Molteno implant. J Glaucoma 2002; 11 : 347-353

25. Ayyala RS, Zurakowski D, Smith JA, et al. A clinical study of the Ahmed glaucoma valve implant in advanced glaucoma. Ophthalmology 1998; 105:1968-1976

26. The AGIS Investigators. The Advanced Glaucoma Intervention Study. 8. Risk of cataract formation after trabeculectomy. Arch Ophthalmol 2001; 119:1771-1780

27. Bellucci R, Perfetti S, Babighian S, et al. Filtration and complications after trabeculectomy and after phaco-trabeculectomy. Acta Ophthalmol Scand Suppl 1997; 224:44-45

28. D'Eliseo D, Pastena B, Longanesi L, et al. Comparison of deep sclerectomy with implant and combined glaucoma surgery. Ophthalmologica $2003 ; 217: 208-211$

29. Hoffman KB, Feldman RM, Budenz DL, et al. Combined cataract extraction and Baerveldt glaucoma drainage implant; indications and outcomes. Ophthalmology 2002; 109:1916-1920 